\title{
Including the people with disabilities at work: a case study of the job of bricklayer in civil construction in Brazil
}

\author{
Martins, L. B ${ }^{\mathrm{a}}$, Barkokébas Junior, $\mathrm{B}^{\mathrm{b}}$ and Guimarães, B. $\mathrm{M}^{\mathrm{c}^{*}}$ \\ ${ }^{a}$ Federal University of Pernambuco, Department of Design, Av. Prof. Moraes Rego, 1235, Cidade Universitária, \\ 50670-901, Recife-PE, Brazil.laurabm@folha.rec.br \\ ${ }^{b}$ University of Pernambuco, Department of Civil Engeneering, Rua Benfica, 455, Bloco I - Madalena \\ 50720-001 - Recife, PE, Brazil.bedalsht@poli.br \\ ${ }^{\mathrm{c}}$ Federal University of Pernambuco, Department of Design, Av. Prof. Moraes Rego, 1235, Cidade Universitária, \\ 50670-901, Recife- PE, Brazil.bmguimaraes@hotmail.com
}

\begin{abstract}
The aim of this paper is to present the results of the evaluation of the job of bricklayer in the construction industry to determine the profile of workers with disabilities who could perform this function and what adjustments are needed. The methods and techniques used in the field study were: direct observation of the activities and the environment, interviews with bricklayers on building sites, a video and photographic record of tasks being carried out to analyze the job of bricklayer, software resources were used. This study set out the disabilities most commonly caused by work accidents in the civil construction industry and simulated the conditions of the individuals to determine whether they could perform the activities of this function and what adaptations are needed. It was observed that workers with hearing impairments could perform activities without any change in the workplace and individuals who had had a leg or foot amputated need to use appropriate prostheses to perform the activities of the function. Thus, it was shown that the activity of professionals with experience in Ergonomics is essential since, by the activity of gathering data and analysing the physical, cognitive and organizational requirements of jobs and by collecting data on and analysing the functional capabilities of the worker with a disability, adaptations to jobs can be adequately defined.
\end{abstract}

Keywords: Ergonomics, Person with a disability, Inclusion at work, Civil Construction

\section{Introduction}

About $23.9 \%$ of the population in Brazil, or 45.6 million people have some type of disability, of which $78 \%$ are visually impaired, $29.09 \%$ have a motor disability, $21.3 \%$ impaired hearing, $5.73 \%$ a mental disability (IBGE, 2011[7]).

Therefore, the inclusion of this population in the social-work environment has been widely discussed and encouraged at the federal and state government levels through various laws and decrees. Among the legal measures adopted by the State, the ones that stand out are Law No. 8.112, of 11/12/1990, which ensures PDs the right that $20 \%$ of the places offered in competitive public entrance examinations are reserved for them Law No. 8213/91 which obliges companies with more 100 than employees to have $2 \%$ to $5 \%$ of their staff as people with disabilities. Although these laws have prompted the opening of places in companies, the number of PDs participating in the labor market is still far below what is wished for (Tanaka, 2005 [6]).

Thus, it is seen that current legislation does not guarantee the inclusion of PDs in the labor market because, as per data from the 2009 Annual Report of Social Information (RAIS), of the total of 41.2 million people with active, formal employment links at 31 December, 288,600 were declared as people with disabilities, which represents $0.7 \%$ of the total of formal employment links (Brazil, 2010 [5]).

Some companies have hired workers with disabilities without adequate methods, i.e. without

\footnotetext{
${ }^{*}$ Corresponding author. Guimarães, B. M. E-mail: bmguimaraes@hotmail.com
} 
prior analysis of accessibility conditions, of the demands of their jobs and of the potential of these people, which has resulted in problems of appropriateness, accidents and both economic losses and damage to the company's image and its social awareness program, apart from psycho-social problems for the PDs (Simonelli and Camarotto, 2005 [12]).

It is verified that the process of inclusion of PDs in the labor market is a difficult task that has encountered some difficulties such as: the lack of professional training of PDs, the presence of architectural and organizational barriers and discrimination as to the PD's functional potential. Thus, it is essential to understand the interactions between people and the elements of the system of work, based on the foundations and methods of Ergonomics so as to enable work to be matched to the functional capabilities of people with disabilities (Guimarães, 2011 [3] ).

Ergonomics has become indispensable both to maximizing the capabilities of the DP as well as so that the occupations available to these workers offer ideal working conditions, both in terms of accessibility and in making the work environment adequate (the physical and organizational structure), particularly avoiding the worsening of the existing impairment or disability and/or the emergence of new ones (Gualberto Filho et al, 2002 [2]).

Thus, Tortosa et al (1997 [9]) state that there is need to compare the demands of work and the capabilities of the PD, i.e. to assess the skills of the individual and determine the demands and requirements of the work activity. The goal is that the demands of the job do not exceed the functional capabilities of the worker with a disability and that the post is accessible and safe.

The objective of comparing the requirements of the job with the functional capacity of the worker with a disability is to verify if the work is less or more demanding than the worker can learn to cope with. Thus, what is avoided is that the DP has to struggle to adapt to the work or that the work is far short of their professional qualifications.

PDs' jobs should allow or facilitate the development of their abilities and individual skills, while also preventing the progression of disabilities that already exist and/or the appearance of new ones (Tortosa et al, 1997 [9]).

The adaptation of jobs to PDs may vary both in the complexity of each case, as in resources needed. Consequently, the planning of each adaptation also varies with time, effort, and the professionals involved, it being important that physiotherapists, engineers, architects, designers and other professionals are present. Moreover, the adaptation process should involve the people affected (the PD, the employer and the co-workers) as active participants so as to achieve a good result (Martins and Guimarães, 2010 [8]).

A job not adapted to the worker with a disability, just as to any worker, will bring losses to the company, such as a fall in productivity, an increase in absenteeism, a greater likelihood of work accidents and errors. It will also adversely affect the worker, because it will lead him to a greater effort to adapt to the job, thus increasing fatigue, stress, unsuitable postures and the risk of musculoskeletal lesions (Oliveira et al, 2001 [11]).

This paper presents the results of evaluating the job of bricklayer in the civil construction industry so as to determine the profile of workers with a disability who could perform this function and what adaptations are needed.

\section{Method}

The field research was carried out between October and December 2010 on a site of a water supply network in the Metropolitan Region of Recife, Pernambuco, Brazil.

The methods and techniques used in the field study were: direct observation of the activities and the environment, semi-structured interviews with the bricklayers of the site, and a video and photographic record of the tasks done. Additionally, in order to analyze the job of bricklayer, ErgoDis/IBV software resources were used, which, according to Ferreras et al (2006) [1] is a software program aimed at adapting jobs for people with physical, mental and/or sensory disabilities and this tool has been validated in several countries.

Therefore, the field research began by surveying the job as laid down and determining a bricklayer's actual work; based on examining the company's documents and interviews with workers doing this job, the safety technician and civil engineer, so as to determine the physical and intellectual demands of the task of the job; by means of verbal information from the Civil Engineer, a specialist in the area of Safety and Hygiene in the Civil Construction Industry, the most common disabilities caused by work in the civil construction industry were defined, since this is an industry that employs few people who have a disability; using the software mentioned, 
simulations were made of individuals with hearing and visual impairments, and those whose fingers, hand, arm, leg and foot had been amputated so as to determine if they could exercise the function analyzed and/or what adaptations are needed; analysis and interpretation of the data collected, with the definition of the causes of mismatches with the the job; and finally, recommendations were drawn up for making the job of bricklayer suitable.

As this was a research study on human beings, it was submitted to and approved by the Committee for Ethics in Research of the Center for Health Sciences of the Federal University of Pernambuco, for which it received the registration number $315 / 10$.

\section{Results}

Using the software program, simulations of 10 hypothetical individuals with various types of disability were made to verify if they could exercise functions of bricklayer and what adaptations were needed.

The hypothetical subject with partial hearing loss, simulated in the software, was moderately deaf, which, according to Article 4 of Decree no. 3.298/99 (BRASIL, 1999 [4]) can hear from and above $41 \mathrm{~dB}$ (A) and did not use a hearing aid. The hypothetical person with a visual impairment had low vision, namely, visual acuity between $30 \%$ and $5 \%$ in his better eye, with the best optical correction. In the hypothetical cases of subjects who had had an arm, hand, leg or foot amputated, the total amputation of one of these structures was considered. Simulated individuals whose fingers and thumb had been amputated presented the total loss of four fingers except the thumb, and the total loss of the thumb, respectively, and were unable to perform the pincer movement and because of this disability were unable to hold objects with that hand.

Work on the site where the research was carried out is from Monday to Thursday from 07:00 to 17:00 and on Friday from 07:00 to 16:00 with a one-hour break for lunch, a total of 44 hours per week. Sometimes it is necessary to do overtime to finalize the steps of the construction as per the schedule established.

The job of bricklayer evaluated is carried out on the construction site of the Water Treatment Plant (WTP) of the Water Supply System in the town of Cabo de Santo Agostinho in the metropolitan area of Recife. At the time of data collection there were 40 workers exercising the function of bricklayer on the site.
The bricklayers are professionals who are characteristic of civil construction sites, and are very important for the construction of concrete structures, masonry and doing the finishing. In the job evaluated, the main functions are to build foundations, and concrete and masonry structures.

\subsection{Description of the work prescribed v. real work}

The description of the prescribed work (task) and the survey of the actual work (activity) was important not only to learn about the bricklayer's work but also to determine the physical and cognitive requirements needed to perform the function. The task was obtained from the documents on PCMAT (Program of Work and Environment Conditions) and LTCAT (Technical Report of the Environmental Conditions of Work) and in order to determine the activities, onsite observations were made, photographs taken and interviews held with two workers of the function, a civil engineer and a security technician, in which they were asked about how each of the tasks was performed.. The description of the prescribed and the corresponding real work can be seen in Table 1 .

\subsection{Analysis of jobs using software programs}

The analysis of PCMAT and LTCAT documents and the interviews with the workers of the function, a civil engineer and security technician, apart from supplying information to determine the real work and the prescribed work, made it viable to feed the software with data related to the work and the environment.

Subsequently, evaluations were made by simulating workers with hearing and visual disabilities, and those whose fingers, hand, arm, leg or foot had been amputated to determine if they could exercise the function and/or what adaptations are needed. The results are presented in Table 2. 
Table 1

Work post of Bricklayer: task $\mathrm{v}$ activity

\begin{tabular}{|c|c|}
\hline Task & Activity \\
\hline 1. Casting concrete & $\begin{array}{l}\text { a. When laying a joist, in a crouching position, he puts the battens in the desired locations } \\
\text { (different movements of the upper limbs). } \\
\text { b. Standing or squatting, holding with both hands the concrete pump, casts concrete in the } \\
\text { place indicated. } \\
\text { c. Depending on the type of concrete, he needs to thicken it, holding the hose of the vibrator } \\
\text { with both hands } \\
\text { d. Squatting, he passes the ruler to level the concrete and make it smooth (different } \\
\text { movements of the upper limbs). } \\
\text { e. After the concrete is cured, if necessary, he undertakes the finishing (described in next } \\
\text { item). }\end{array}$ \\
\hline 2. Doing finishing & $\begin{array}{l}\text { a. With a trowel in one hand, he picks up the mortar in the wheelbarrow and puts it in the } \\
\text { place where the finish will be done (different movements of the upper limbs). } \\
\text { b. Passes the trowel to level the place of the finishing (different movements of the upper } \\
\text { limb). } \\
\text { c. Removes excess mortar and puts it back in the wheelbarrow (different movements of the } \\
\text { upper limb). } \\
\text { d. In finishing with a tamper, he grips it with one hand and passes it over the concrete to give } \\
\text { the finishing (diverse movement of the upper limb). }\end{array}$ \\
\hline 3. Constructing foundations & $\begin{array}{l}\text { a. Standing or squatting, holding with both hands the concrete pump, he casts concrete into } \\
\text { the excavated site. } \\
\text { b. Depending on the type of concrete, he needs to thicken it, holding the hose of the vibrator } \\
\text { with both hands. } \\
\text { c. After the concrete has set and the moulds removed, he does the finishing, if necessary } \\
\text { (already described). }\end{array}$ \\
\hline 4. Building masonry structures & $\begin{array}{l}\text { a. Standing, he picks up the mortar from the wheelbarrow with the trowel, placing it under } \\
\text { the spot where the brick will be placed. If there is already a brick there, he puts it on top of } \\
\text { it (different movements of the upper limb). } \\
\text { b. Removes the brick from the ground by hand (different movements of the upper limb and } \\
\text { c. Punk). } \\
\text { d. Beat with the trowel on top of the brick (elbow flexion-extension). } \\
\text { e. Removes the excess mortar around the brick (various movements of the upper limb). } \\
\text { f. Returns the excess mortar to the wheel-barrow (different movements of the upper limb). } \\
\text { g. Visually checks the brick is in place. } \\
\text { h. Checks the plumb. } \\
\text { i. May break a brick to fill space (different movements of the upper limb). }\end{array}$ \\
\hline $\begin{array}{l}\text { 5. Putting up cladding and laying } \\
\text { sub-flooring }\end{array}$ & $\begin{array}{l}\text { a. Crouching, he puts the batten in the desired locations (different movements of the upper } \\
\text { b. He throws mortar on the location indicated (various movements of the upper limb). } \\
\text { b. Spreads the mortar with the trowel (different movements of the upper limb). } \\
\text { c. After the mortar has set, he lays ceramic tiles on it (different movements of the upper } \\
\text { d. Aluter } \\
\text { e. Beats with his hand or with a rubber mallet on the ceramic to make it settle better (different } \\
\text { movements of the upper limb). } \\
\text { f. Checks the alignment. } \\
\text { g. May need to cut the ceramic to make corners. Leans with one hand on the ceramic and with } \\
\text { the other handles the Makita power cutter or manual tile-cutter to cut the ceramic to the } \\
\text { correct degree. } \\
\text { h. Application of grouting (different movements of the upper limb). } \\
\text { i. Cleaning the ceramic with a cloth or burlap (different movements of the upper limb). }\end{array}$ \\
\hline
\end{tabular}


Table 2

Result of the evaluations using software

\begin{tabular}{|c|c|c|}
\hline Bricklayer & Result & Adaptations \\
\hline Partial hearing disability & Acceptable without changes & \\
\hline Total hearing disability & Acceptable without changes & \\
\hline Partial visual disability & Unacceptable & \\
\hline Total visual disability & Unacceptable & \\
\hline Thumb amputated & Unacceptable & \\
\hline Fingers amputated & Unacceptable & \\
\hline Hand amputated & Unacceptable & \\
\hline Arm amputated & Unacceptable & \\
\hline Leg amputated & Acceptable with changes & $\begin{array}{l}\text { To use prosthetic leg to facilitate movement over the } \\
\text { construction site, which allows handling of objects and tools } \\
\text { with both hands while standing or moving around. }\end{array}$ \\
\hline Foot amputated & Acceptable with changes & $\begin{array}{l}\text { To use a prosthetic foot to facilitate moving about the } \\
\text { construction site, which allows handling of objects and tools } \\
\text { with both hands while standing or moving around. }\end{array}$ \\
\hline
\end{tabular}

Thus, from the results found by the software checks it was verified that only workers with partial and total hearing loss, and leg or foot amputees could exercise the function of bricklayer. The hypothetical worker with a partial hearing loss (moderate deafness) due to the level of hearing loss, has no limitation in listening and communicating with other workers, so the result determined was acceptable without changes. If the level of hearing loss were greater, the use of a hearing aid could be recommended. An individual with total hearing loss would have difficulty in communicating with other workers. However, this can be overcome by means of communicating by gesture and lip reading, and does not impede him from performing the activities of the function, so the result was acceptable without changes. Workers whose leg or foot has been amputated may exercise a bricklayer's activities if they use prostheses for the leg or foot, thus facilitating their moving about the construction site and allows them to handle objects and tools on moving about and when standing, Therefore, this particular result was acceptable with changes.

In the hypothetical cases of workers whose arm, hand or fingers has been amputated, the result was unacceptable because the activities undertaken require movements and strength in both upper limbs.

As to the individuals whose thumb had been amputated, the result was unacceptable, because despite the possibility of using a fixed prosthesis to perform the activities he would be exposed to grave and imminent risk on climbing up scaffolding to do finishing and concreting of vertical structures. According to Regulatory Norm No. 3, the situation of grave and imminent risk is any environmental condition that may cause an accident at work or an occupational disease with a lesion that is serious for the worker's physical integrity (MTE, 2010 [10]).

With respect to the subject with partial visual impairment, he will present a lot of difficulty due to the requirement of visual acuity to perform the tasks of building foundations, masonry structures and doing finishing, so this deemed an unacceptable result. In the case of a worker with total visual impairment, the result was unacceptable, because he cannot carry out the activities of the function due to the need for vision to perform the tasks.

\section{Discussion}

Thus, the importance of the three areas of ergonomics is verified, since by using Physical ergonomics, information can be obtained regarding the postures and movements needed to perform the tasks. Based on Cognitive Ergonomics, the need for the worker to reason and make decisions when undertaking the activity is determined. The importance of Organizational Ergonomics is related to the distribution of tasks and the workload of the jobs. 
Thus, by knowing the task, the physical, cognitive and organizational requirements of the jobs and with the determination of the functional capabilities of the worker with a disability, adaptations to the job can be carried out adequately. Therefore, it is important that the survey, the data analysis and the physical, cognitive and organizational recommendations be made by professionals with experience in ergonomics.

The results of the research showed that only workers with full and partial hearing loss could exercise the function of bricklayer with no change being made to the working environment. Individuals whose leg or foot has been amputated may also exercise the duties of the job evaluated, but only if they use suitable prostheses for their leg or foot.

Due to the lack of published articles on the topic of the inclusion of people with a disability in the civil construction industry, it is recommended that further studies in this production sector be conducted with the objective of facilitating the process of inserting individuals with disabilities into work, facilitating compliance with the law on quotas and improving the adaptation of the job to the PD.

\section{References}

[1] A. Ferreras, et al, Ergonomic adaptation of workplaces for people with disabilities: case studies. In: Proceedings IEA Congress - Meeting Diversity in Ergonomics, 2006, Anais, Eur. Erg. Elsevier Ltd, 2006.

[2] A. Gualberto Filho, et AL, Uma visão ergonômica do portador de deficiência (mesa redonda). In: VII Congresso LatinoAmericano de Ergonomia. I Seminário Brasileiro de Acessibilidade Integral. XII Congresso Brasileiro de Ergonomia, 2002, Recife/PE, Anais, Recife/PE, 2002.

[3] B.M. Guimarães, Exigências da tarefa e o perfil dos trabalhadores com deficiência: um estudo de caso na construção civil usando o software ErgoDis/IBV. Master's Dissertation, University of Pernambuco, 2011.
[4] Brasil. Decreto $\mathrm{n}^{\circ} 3.298$, de 20 de dezembro de 1999. Available at: http://www.planalto.gov.br/

[5] Brasil. Ministério do Trabalho e Emprego. RAIS - Relação Anual de Informações Sociais, 2000 a 2009. Available at: $<$ http://www.mte.gov.br/pdet/index.asp $>$. Accessed on: 01 Nov. 2010.

[6] E.D.O.M. Tanaka, J.O. Eduardo, O que os empregadores pensam sobre o trabalho da pessoa com deficiência? Revista Brasileira de Educação Especial, Marília, v. 11, n. 2, 2005, pp. 273-294.

[7] IBGE - Instituto Brasileiro de Geografia e Estatística. Tabulação Avançada do Censo Demográfico 2010. Rio de Janeiro: IBGE, 2011.

[8] L.B. Martins; B.M. Guimarães, Ergonomia e a inclusão laboral de pessoas com deficiência. Revista Brasileira de Tradução Visual. v. 3, n. 3, 2010.

[9] L. Tortosa, et al. Ergonomia y Discapacidad. Madrid: Ministerio de Trabajo y Asuntos Sociales, 1997.

[10]MTE - Ministério do Trabalho e Emprego. Norma Regulamentadora $\mathrm{n}^{\mathrm{o}} 3$ - Embargo ou interdição. 2010. Available at: http://www.planalto.gov.br/

[11] S.C.F. Oliveira, A.F. Tomaz, A.B. Barbosa Filho, N.M.G. Lucena, A. Gualberto Filho, Adaptação de postos de trabalho ocupados por pessoas portadoras de deficiência física. In: $11^{\circ}$ Congresso Brasileiro de Ergonomia, 2001, Gramado/RS, Anais, Gramado/RS, 2001.

[12] Simonelli, A. P.; Camarotto, J. A. Método de análise de tarefas industriais como ferramenta para a inclusão de portadores de necessidades especiais no trabalho. Rev. Ter. Ocup. Univ. São Paulo, v. 16, n. 3, 2005, pp. 13-146. 